\title{
Rank Order Wise Extent of Awareness of Paddy Growers Regarding Indigenous Technical Knowledge Practices in Bastar District of Chhattisgarh, India
}

\author{
Venkteshwar Jallaraph ${ }^{1 *}$ and K. N. Pathak ${ }^{2}$
}

\author{
${ }^{1}$ Dept. of Extension Education, Jawaharlal Nehru Krishi Vishwa Vidyalaya, Jabalpur (482 004), India \\ ${ }^{2}$ Dept. of Extension Education, Rajmata Vijayaraje Scindia Krishi Vishwa Vidyalaya, Gwalior (474 002), India
}

\author{
Corresponding Author \\ Venkteshwar Jallaraph \\ e-mail: vjallaraph@gmail.com
}

\author{
Article History \\ Article ID: 3 C0551 \\ Received in $22^{\text {nd }}$ October, 2017 \\ Received in revised form $20^{\text {th }}$ August, 2018 \\ Accepted in final form $31^{\text {st }}$ August, 2018
}

\begin{abstract}
This study was conducted in Bastar district of Chhattisgarh state during 2015-16 to know the awareness level of indigenous technical knowledge of paddy growers in paddy cultivation. The Ex-Post-Facto research design was used for the study. This design was considered appropriate because the phenomenon has already occurred. The sample has been selected through multi-stage sampling technique. Bastar district was selected purposively for study because of paddy is the main crop in that area. There are seven blocks (Bastanar, Darbha, Bakawand, Bastar, Jagdalpur, Tokapal and Lohandiguda) in Bastar district among which two blocks (Tokapal and Lohandiguda) were selected for study. Six villages were selected from each block. From each of the selected villages, 10 respondents were selected by simple random sampling procedure, thus the sample size for the study was 120. The primary data were collected through personal interview technique with the help of pre-tested interview schedule. Various statistical measures viz., mean, standard deviation and mean score were used for analyzing the data. In present study it was found that higher per cent of paddy growers (46.66\%) had high level of awareness regarding Indigenous Technological Knowledge practices, followed by medium (39.17\%) and low (14.17\%), respectively. The highest extent of rank order wise awareness about field preparation and ploughing practices were $\mathrm{I}^{\text {st }}(2.94)$, followed by irrigation management practices (2.90) $\mathrm{II}^{\text {nd }}$ and plant protection measure practices $(2.87) \mathrm{II}^{\mathrm{rd}}$.
\end{abstract}

Keywords: Extent of awareness, ITK, local knowledge, sustainable development

\section{Introduction}

Indigenous Peoples with centuries of their intimate links and relationship with nature has broad knowledge base on the complex ecological system. They have a clear perception on the bio-resource for generating ecological services and on which their entire life depend, that they have effectively developed a stake in managing and conserving the bioresources in their surroundings (Martemjen et al., 2013). The indigenous technical knowledge is the localized knowledge, transmitted from generation to generations and time tested by local community to solve the particular problems taking cognizance of local factors. It is based on resource conservation to the betterment of next generations. These resource conservation attitudes of indigenous technical knowledge foster the sustainability and sustainable agriculture is the urgent need to conserve the agricultural resources for next generations (Banerjee, 2011). Indigenous knowledge is the knowledge of indigenous people inhabiting different geographical region of the world with their own language, culture, tradition, belief, folklore, rites and rituals (Chhetry and Belbahri, 2009). Indigenous knowledge is type of knowledge, which has evolved within the community and has been passed on from one generation to another (Natarajan and Govind, 2006). The farmers from different ethnic diversity of the region have developed their own systems in cultivation of various crops (Sharma and Gogoi, 1999).

Indigenous Technical Knowledge (ITK) is the product of centuries of trial and error, natural selection and keen observation that can form the knowledge base on which researchers and extension workers can plan their research strategy and experimental procedures. Thus, peoples' knowledge is more detailed than that of others, who have not had the same experience or do not have the same skills in observation or analysis (Sankaran, 2005). Indigenous technical knowledge (ITK) is the knowledge that people in given community have developed. It is based on experience, often tested over long period of use, adapted to local culture and environment, dynamic, changing and lay emphasis on minimizing risk rather than maximizing profits. Knowledge, skill and survival strategy of farmers operating with low external inputs have often ignored to promote modern agriculture (Haverkort and Zeeum, 1992). Indigenous Knowledge is the 
local knowledge that is unique to a given culture or society. It is the basis for agriculture, health care, food preparation, environmental conservation and a host of other activities. It is a people derived science and it represents people's creativity, innovations and skills (Ulluwishewa, 1993).

The concept of sustainable agriculture in late eighties in Indian agricultural scenario has evoked interest on indigenous technical knowledge (ITK) that has the element of use of natural products to solve the problems pertaining to agriculture and allied activities. Indigenous rice landraces have been associated with ethnic cultivation techniques. Ethnic and socio-religious life affects the survival of these landraces under the scenario of a disappearing indigenous rice biodiversity. Biodiversity observed in their morphological and physiological characters, tolerance to stress and response to different traditional agro techniques (Sen et al., 2016). Rice is most important cereal crop. India is the second largest producer of rice in the World next to china having $44.11 \mathrm{mha}$ area, 105.48 $\mathrm{mt}$ production and $2391 \mathrm{~kg} \mathrm{ha}^{-1}$ productivity. In Chhattisgarh rice occupies an area of 3.81 mha with production of $6.32 \mathrm{mt}$ with average productivity $1660 \mathrm{~kg} \mathrm{ha}^{-1}$ (Anonymous, 2016). Rice as a food crop is cultivated throughout the country by all farmers (tribals to most progressive farmers) there are lots of native technologies evolved over a period of time.

\section{Materials and Methods}

The study was conducted in Bastar district of Chhattisgarh, India. There are seven blocks viz., Bastanar, Darbha, Bakawand, Bastar, Jagdalpur, Tokapal and Lohandiguda. Among these two blocks viz., Tokapal and Lohandiguda were selected purposively in 2015-16 because of paddy is the main kharif crop in that area. The Ex-Post-Facto research design was used for the study. The sample has been selected through multi-stage sampling technique. From each selected block, six villages were randomly selected. The villages selected were Karanji, Metawada, Arandwal, Tokapal, Koypal, Rajoor from Tokapal block and Karkapal, Chitrakot, Belar, Takraguda, Usaribeda, Gadiya from Lohandiguda. Thus total 12 villages were selected for the study. From each of the selected villages, 10 respondents were selected by simple random sampling procedure, thus the sample size for the study was 120 . The data were collected through personal interview technique with the help of an interview schedule. The statistics applied were percentage, mean and mean score. The awareness level was measured by using a set of practices of indigenous technical knowledge for paddy cultivation was prepared. In the awareness level, there were 27 practices. The weightage of 3 for high awareness, 2 for medium and 1 for low awareness were assigned for each practice. Thus maximum obtainable score of awareness was 81 ; whereas minimum could be 27 and extent of awareness was calculated by following formula.

Sum of the awareness

Awareness index $=\frac{\text { scores obtained by respondent }}{\text { Sum of obtainable awareness score }} \times 100$

\section{Results and Discussion}

3.1. Practice wise awareness regarding indigenous technological knowledge practices among paddy growers

The study showed in Table 1 that the $46.66 \%$ paddy growers belonged to high level category with respect to overall level of awareness about ITK practices in paddy cultivation. On analyzing practice wise level of awareness of ITK in paddy cultivation it was found that majority $(76.67 \%)$ traditional

Table 1: Distribution of practice wise indigenous technical knowledge

\begin{tabular}{|c|c|c|c|c|c|}
\hline \multirow[t]{2}{*}{ SI. No. } & \multirow[t]{2}{*}{ Indigenous technical knowledge } & \multicolumn{3}{|c|}{ Awareness Level } & \multirow{2}{*}{$\begin{array}{l}\text { Mean } \\
\text { score }\end{array}$} \\
\hline & & Low & Medium & High & \\
\hline \multicolumn{6}{|c|}{ I. Field preparation and ploughing } \\
\hline 1. & Deep summer ploughing & $14(11.67)$ & $37(30.83)$ & $69(57.50)$ & $3.03^{*}$ \\
\hline 2. & Through indigenous (Desi) plough & $12(10.00)$ & $28(23.33)$ & $80(66.67)$ & $3.23^{*}$ \\
\hline 3. & Removal of crop residues through bukkher & $11(09.17)$ & $57(47.50)$ & $52(43.33)$ & 2.78 \\
\hline 4. & Use of pata for field leveling & $16(13.33)$ & $54(45.00)$ & $50(41.67)$ & 2.7 \\
\hline Averag & mean score & $13(10.83)$ & $44(36.67)$ & $63(52.50)$ & 2.94 \\
\hline \multicolumn{6}{|c|}{ II. Pre-sowing treatment of seeds } \\
\hline 1. & Sun drying & $14(11.67)$ & $46(38.33)$ & $60(50.00)$ & $2.88^{*}$ \\
\hline 2. & Use of brine (salt) solution & $30(25.00)$ & $58(48.33)$ & $32(26.67)$ & 2.28 \\
\hline Averag & nean score & $22(18.33)$ & $52(43.33)$ & $46(38.33)$ & 2.58 \\
\hline \multicolumn{6}{|c|}{ III. Method of sowing } \\
\hline 1. & Kurra boni (Dry seeding) & $17(14.17)$ & $56(46.66)$ & $47(39.17)$ & 2.64 \\
\hline 2. & Chitka boni & $12(10.00)$ & $57(47.50)$ & $51(42.50)$ & 2.75 \\
\hline 3. & Choppi boni after mansson starts & $09(07.50)$ & $44(36.67)$ & $67(55.83)$ & $3.04^{*}$ \\
\hline
\end{tabular}




\begin{tabular}{|c|c|c|c|c|c|}
\hline \multirow[t]{2}{*}{ SI. No. } & \multirow[t]{2}{*}{ Indigenous technical knowledge } & \multicolumn{3}{|c|}{ Awareness Level } & \multirow{2}{*}{$\begin{array}{l}\text { Mean } \\
\text { score }\end{array}$} \\
\hline & & Low & Medium & High & \\
\hline Average & mean score & $13(10.83)$ & $52(43.33)$ & $55(45.83)$ & 2.81 \\
\hline \multicolumn{6}{|c|}{ IV. Selection of seeds } \\
\hline 1. & Selection of healthy panicles from field & $14(11.67)$ & $71(59.16)$ & $35(29.17)$ & 2.47 \\
\hline 2. & Selection of bold seeds through Supa & $13(10.83)$ & $51(42.50)$ & $56(46.67)$ & $2.83^{*}$ \\
\hline 3. & Separation of floating seeds in water & $15(12.50)$ & $48(40.00)$ & $57(47.50)$ & $2.83^{*}$ \\
\hline 4. & Soaking of seeds for germination & $18(15.00)$ & $38(31.67)$ & $64(53.33)$ & $2.92^{*}$ \\
\hline Average & mean score & $15(12.50)$ & $52(43.33)$ & $53(44.17)$ & 2.76 \\
\hline \multicolumn{6}{|c|}{ V. Manure application } \\
\hline 1. & Use of decomposed FYM (Farm Yard Manure) & $14(11.67)$ & $20(16.66)$ & $86(71.67)$ & $3.32^{*}$ \\
\hline 2. & Use of compost & $39(32.5)$ & $57(47.50)$ & $24(20.00)$ & 2.08 \\
\hline Average & mean score & $26(21.67)$ & $39(32.50)$ & $55(45.83)$ & 2.7 \\
\hline \multicolumn{6}{|c|}{ VI. Weed control } \\
\hline 1. & Traditional biasi method & $16(13.33)$ & $12(10.00)$ & $92(76.67)$ & $3.40^{*}$ \\
\hline 2. & Eradication of weeds with hands & $16(13.33)$ & $48(40.00)$ & $56(46.67)$ & 2.8 \\
\hline Average & mean score & $16(13.33)$ & $30(25.00)$ & $74(61.67)$ & 2.81 \\
\hline \multicolumn{6}{|c|}{ VII. Irrigation management } \\
\hline 1 & Irrigation through outer channel & $17(14.17)$ & $57(47.50)$ & $46(38.33)$ & 2.63 \\
\hline 2 & Water locking in the field & $13(10.83)$ & $30(25.00)$ & 77 (64.17) & $3.18^{*}$ \\
\hline Average & mean score & $15(12.50)$ & $44(36.67)$ & $61(50.83)$ & 2.9 \\
\hline \multicolumn{6}{|c|}{ VII. Plant protection measures } \\
\hline 1. & Use of neem carnel for termite control & $15(12.50)$ & $38(31.67)$ & $67(55.83)$ & $3.25^{*}$ \\
\hline 2. & Use of karra (Karla) trees sticks & $60(50.00)$ & $52(43.33)$ & $08(06.67)$ & $2.99^{*}$ \\
\hline 3. & Collection and destruction of insects with hands & $16(13.33)$ & $34(28.33)$ & $70(58.34)$ & 2.72 \\
\hline 4. & Complete locking in the field through water & $28(23.33)$ & $57(47.50)$ & $35(29.17)$ & $3.03^{*}$ \\
\hline 5. & Use of FYM slurry for disease control & $04(03.33)$ & $39(32.50)$ & $77(64.17)$ & 2.35 \\
\hline Average & mean score & $15(12.50)$ & $45(37.50)$ & $60(50.00)$ & 2.87 \\
\hline \multicolumn{6}{|c|}{ IX. Storage Management } \\
\hline 1. & Bins made by mud, cow dung and rice husks & $13(10.83)$ & $45(37.50)$ & $62(51.67)$ & $2.93^{*}$ \\
\hline 2. & Use of gunny bags & $23(19.17)$ & $59(49.17)$ & $38(31.67)$ & 2.44 \\
\hline 3. & Use of fertilizer bags & $24(20.00)$ & $59(49.17)$ & $37(30.83)$ & 2.42 \\
\hline \multicolumn{2}{|c|}{ Average mean score } & $20(16.67)$ & $54(45.00)$ & $46(38.33)$ & 2.59 \\
\hline \multicolumn{2}{|c|}{ Overall Extent of awareness about ITK } & $17(14.17)$ & $47(39.17)$ & $56(46.66)$ & 2.79 \\
\hline
\end{tabular}

${ }^{*}$ Higher than the average mean score

biasi method, followed by use of decomposed FYM (Farm Yard Manure) (71.67\%), ploughing through indigenous (Desi) plough (66.67\%), use of FYM slurry for disease control $(64.17 \%)$, water locking in the field $(64.17 \%)$, collection and destruction of insects with hands (58.34\%), deep summer ploughing $(57.50 \%)$, choppi boni after mansson starts (55.83\%), use of neem carnel for termite control (55.83\%), soaking of seeds for germination (53.33\%), sun drying $(50.00 \%)$, separation of floating seeds in water $(47.50 \%)$, selection of bold seeds through Supa (46.67\%), eradication of weeds with hands $(46.67 \%)$ and bins made by mud, cowdung and rice husks (51.67\%).

In case of medium level of awareness category it was found that majority of the respondents $(59.17 \%)$ had selection of healthy panicles from field and threshing floor, followed by use of gunny bags (49.17\%), use of fertilizer bags (49.17\%), use of brine solution (48.33\%), removal of crop residues through 
bukkher (47.50\%), chitka boni (47.50\%), use of compost $(47.50 \%)$, irrigation through outer channel $(47.50 \%)$, kurra boni (Dry seeding) (46.66\%) and use of pata for field leveling (45.00\%). In case of low level of awareness it was found use of karra (Karla) trees sticks (50.00\%)

\subsection{Extent of awareness regarding indigenous technical knowledge practices}

The findings presented in Table 2 revealed that the high per cent of paddy growers $(46.66 \%)$ were found to have high awareness, followed by medium awareness (39.17\%) and low awareness (14.17\%) regarding indigenous technical knowledge practices respectively. Similar results are also reported by Sheikh et al. (2006) and Mbanaso et al. (2012). The category wise mean score for indigenous technical knowledge practices was found least for low awareness ( 0.14 ) followed by medium awareness (0.78) and high awareness (1.87) respectively. The overall mean score of awareness regarding indigenous technical knowledge practices was found to 2.79 .

Table 2: Distribution of paddy growers according to their extent of awareness

\begin{tabular}{llccc}
\hline Attributes & Categories & $\begin{array}{c}\text { No. of re- } \\
\text { spondents }\end{array}$ & Percentage & $\begin{array}{c}\text { Mean } \\
\text { score }\end{array}$ \\
\hline Awareness & Low & 17 & 14.17 & 0.14 \\
& Medium & 47 & 39.17 & 0.78 \\
& High & 56 & 46.66 & 1.87 \\
Total & & 120 & 100.00 & 2.79 \\
\hline
\end{tabular}

Table 3 shows that the paddy growers found to have highest awareness in respect of field preparation and ploughing practices with average mean score 2.94 and ranked I, followed

Table 3: Rank order wise extent of awareness of paddy growers about ITK practices in paddy cultivation

\begin{tabular}{llcc}
\hline S I. & Indigenous technological knowl- & \multicolumn{2}{c}{ Rank order wise } \\
No. & edge practices & Mean score & Rank \\
\cline { 3 - 4 } & & $2.94^{*}$ & $\mathrm{I}$ \\
\hline 1. & Field preparation and ploughing & 2.58 & $\mathrm{IX}$ \\
2. & Pre-sowing treatment of seeds & $2.81^{*}$ & $\mathrm{IV}$ \\
3. & Method of sowing & 2.76 & $\mathrm{VI}$ \\
4. & Selection of seeds & 2.70 & $\mathrm{VII}$ \\
5. & Manure application & $2.81^{*}$ & $\mathrm{~V}$ \\
6. $\quad$ Weed management & $2.90^{*}$ & $\mathrm{II}$ \\
7. $\quad$ Irrigation management & $2.87^{*}$ & $\mathrm{III}$ \\
8. $\quad$ Plant protection measures & 2.59 & $\mathrm{VIII}$ \\
9. $\quad$ Storage management & 2.79 & \\
Overall level of awareness about ITK in \\
paddy cultivation
\end{tabular}

"Higher than the overall mean score by irrigation management practices with average mean score 2.90 and ranked II, Plant protection measure practices ranked III with average mean score 2.87, Method of sowing ranked IV with average mean score 2.81 , weed management practices ranked $\mathrm{V}$ with average mean score 2.81 , selection of seeds practices ranked VI with average mean score 2.76, manure application practices ranked VII with average mean score 2.70, storage practices ranked VIII with average mean score 2.59 and pre-sowing treatment of seeds ranked IX with average mean score 2.58, respectively. The overall mean score was 2.79 .

\section{Conclusion}

Paddy growers had high level of awareness regarding indigenous technological practices in paddy cultivation, followed by medium and low. The highest extent of rank order wise awareness about field preparation and ploughing practices were $\mathrm{I}^{\text {st }}(2.94)$, followed by irrigation management practices $(2.90) \mathrm{II}^{\text {nd }}$ and plant protection measure practices (2.87) $\mathrm{III}^{\text {rd }}$.

\section{References}

Anonymous, 2016. Agricultural Statistics at a Glance. Directorate of Economics and Statistics. Department of Agriculture, Cooperation \& Farmers Welfare. Ministry of Agriculture \& Farmers Welfare. Government of India, 88-89.

Banerjee, G.C., 2011. A textbook of animal husbandry. Oxford and IBH publishing Co. Pvt. Ltd., New Delhi, India.

Chhetry, G.K.N., Belbahri, L., 2009. Indigenous pest and disease management practices in traditional farming systems in north east India. A review. Journal of Plant Breeding Crop Science 1(3), 28-38.

Haverkort, B., de - Zeeum, H., 1992. Development of technologies towards sustainable agriculture: institutional implications, In: Agriculture Extension: Worldwide Institutional Evolution and Forces for changes, edited by Rivera, W.M., Gustafson, D.J., 231-242.

Martemjen, Lanusashi, Tiakumla, 2013. Indigenous Techniques and Practices for Management of Bio-resources: a Naga Experience. International Journal of Bio-resource and Stress Management 4(4), 648-650.

Mbanaso, E.O., Agwu, A. E., Anyanwu, A. C., Asumugha, G. N., 2012. Assessment of the extent of adoption of sweet potato production technology by farmers in the southeast agro-ecological zone of Nigeria. Journal of Agriculture and Social Research 12(1), 124-136.

Natarajan, Santha, G., 2006. Indigenous agricultural practices among tribal women. Indian Journal of Traditional Knowledge 5(1), 118-126.

Sankaran, P.N., 2005. Indigenous Knowledge: Resource for sustainable development. Employment News, Weekly, Publications Division, Ministry of I and B, New Delhi 30(2), 1-48. 
Sen, D., Maity, S.K., Sarkar, N.C., 2016. Studies on Existing Indigenous Rice Landraces and their Survival Strategies at Old Alluvial Region of North and South Dinajpur, West Bengal, India- A Case Study. International Journal of Bio-resource and Stress Management 7(3), 437-443.

Sharma, K.K., Gogoi, R., 1999. Agricultural traditional wisdom of Assam. Assam Agri-History 3(3), 199-206.

Sheikh, A.D., Mahmood, M.A., Bashir, A., Khasif, M., 2006.
Adoption of rice technological package by the farmers of irrigated Punjab. Journal of Agriculture Research 44(4), 341-352.

Ulluwishewa, R., 1993. Indigenous Knowledge System for Sustainable Development. The Case of Pest Control by Traditional Paddy Farmers in Shrilanka. Indigenous Knowledge and Development Monitor 1(1), 51-63. 